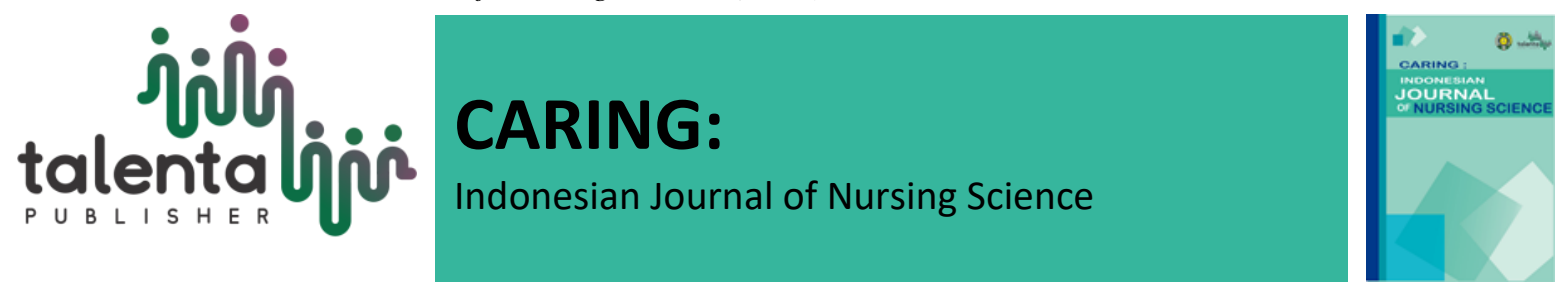

\title{
Psychosocial Care Service in the Mental Health Provision
}

\section{Roxsana Devi Tumanggor}

Lecturer of Psychiatry and Community Nursing Department, Faculty of Nursing, Universitas Sumatera Utara - Indonesia

\begin{abstract}
The approach of health service can be divided into a medical term and psychosocial term that are applied by the mental health professional. The mental heath services help their clients with mental illness by giving a specific treatments particularly from psychological view. The information in this essay were collected from two databases that are CINAHL and Health Science. It also included the University of Wollongong ejournal database for nursing program. Based on the internet research, it is imperative that the intervention can be delivered in the form of case management. This paper therefore will discuss the psychosocial care for mentally ill clients in terms of concept, components, interventions and benefit in the practical area. The strategies to develop the treatment more effective are also discussed in depth.
\end{abstract}

Keywords. psychosocial care, medical care, mental health.

Received 10 June 2020 | Revised 11 June 2020| Accepted 15 June 2020

\section{Introduction}

Psychosocial care is developed from the recovery framework proposed by Anthony (Anthony 1993; Bridges et al 1994). The focus of the framework is a social functioning improvement rather than pathological issue such as the neurobiological issue, the brain damaging and genetic issue. The interventions of psychosocial care are delivered in some aspects, such as cognitive training, psycho education, social skill training, cognitive behavioural therapy, case management, motivational interviewing, self-help groups, counselling and family therapy (Pitschel-Walz et al 2009; Tsuang et al 2006; Amato et al 2009).

The aim of the service is to support the family and the clients in psycho education. The clients need skills and knowledge to cope with daily life problems while the family need support regarding their mentally ill family members (Bridges et al 1994, Harvard Mental Health Letter 2001). The coordination among the clients, the family and the mental health professional are needed to support clients' recovery.

\footnotetext{
*Corresponding author at: Jl. Prof. Maas no. 3 Kampus USU, Medan - Indonesia

Corresponding email: roxsana.tumanggor@usu.ac.id

Copyright @ Published by Talenta Publisher, ISSN: 2580-6769 e-ISSN: 2580-829X

Journal Homepage: https://talenta.usu.ac.id/IJNS
} 


\section{Research Methods}

Internet research were conducted to gather information related to psychosocial care and medical care. The databases included CINAHL, Health Science and University of Wollongong EJournal Database for Nursing Program. All literatures were analyzed and chosen with some keywords, such as psychosocial care, mental health, and medical care.

\section{Result and Discussion}

According to the internet research, there were three main points that build a psychosocial care in mental health delivery. It includes the description of the psychosocial care, how it would be different with medical care and how to build an improvement in the provision of psychosocial care in the future. All of this analysis are explored in depth to get an insight how to integrate psychosocial care for mentally ill clients.

\subsection{The Components and Interventions of Psychosocial Care}

The psychosocial care has ten components, that are self-direction, individualized, empowerment, holistic, non-linear care, strength-based treatment, peer support, respect, responsibility and hope (Caldwell et al 2010). However, the key components in the psychosocial treatment is to build 'hope' since its effectiveness depends on the motivation of the clients in rehabilitation (Anthony 1993). In order to deliver the components and make the interventions more effective, it is needed to establish a case management system in the treatment. This case management is arranged either in the inpatient unit or in the community service by various professionals. The collaboration provision assesses the clients' preferences since the admission until discharging from the hospital (Herrman et al 2002). Therefore, the need for a spesific tool in psychiatric assesments need to be addressed. It assists the mental health staff to identify more spesific in mental illness cases (Chalifoux et al 1996). In addition, it also helps in preventing a confusion among the mental health professionals for biased diagnoses (Secker et al 2000).

\subsection{The Medication Versus the Psychosocial Care}

The medication approach reveals more disadvantages compared with non-medication approach (Harvard Mental Health Letter 2001). Studies conducted by some researchers (e.g., Olfson et al 2006) from 1997 to 2007 in a mental health service showed that the medication approach caused the mental illness symptoms increased, the incidences of drug abuse went up due to irregular taking medication (Coldham et al 2002), the incidents of relapse grew and the negative impacts of medication still existed (Nose et al 2003; Verdoux et al 2000). Moreover, it also found that the medication triggered hostile behaviours towards the medical staff (Fenton et al 1997). Therefore, the medication approach has been suggested to be re-examined (Miklowitz et al 2007). 
On the other hand, the psychosocial care as a non-medical method reveals some positive outcomes on several studies. It shows reduction of psychiatric symptoms of severe mental illness (Bradshaw \& Roseborough 2004; Harvard Mental Health Letter 2001), increases the self-insight in term of psycho education (Pitschel-Walz et al 2009), improves the quality of life of chronic mentally ill clients (Browne 1999; Tsuang et al 2006), increases social functioning skills (Miklowitz et al 2007), creates an effective treatment and efficient in budget (Bustillo et al 2001), is highly effective in case of anxiety disorders (Olatunji et al 2010) and provides an effective intervention for psychiatric clients with a non-adherence history (Nose et al 2003). It is obviously proved that the psychosocial treatments make a good progress for mentally ill clients in every aspect of their lives.

\subsection{The Strategies in Developing the Psychosocial Care}

There are four possibilities to make the intervention of psychosocial approach more effective. They are as follows:

1. Encourage the mental health policy in the arrangement of work case load, limiting Community Psychiatric Nurse/CPN time in community service in order to minimise the incidence of burn-out in coordination among the professional (Bridges et al 1994; Secker et al 2000; Simpson 2005).

2. Improve the skills in therapeutic communication for clients' engagement in the service for a better outcome (MacNeela et al 2010; Roe \& Swarbick 2007; Marder et al 1983 in Fenton et al 1997). It is clearly described that effective communication as the key in psychiatric nursing revealed a good response for a crisis intervention in terms of comfort, anxiety and the clients' satisfaction (MacNeela et al 2010; Shattel et al 2007).

3. Promote the involvement of the consumers in mental health service area and the policies related to their illness (Caldwell et al 2010).

4. Build the combination of the medication approach and the psychosocial service in order to maintain a good relationship among professionals in mental health care and improve the social functioning among the mentally ill clients (Roe \& Swarbick 2007; Herrman et al 2002; Amato et al 2009).

\section{Conclusion}

The psychosocial care is the reflection of recovery framework in the mental health provision. It has a structured interventions with ten components in the application practices. It is conducted in a continous, integrated and comprehensive ways in order to make the improvement in daily life of mentally ill clients. Therefore, the psychosocial care should be proposed for clients's ability in social functional. Some strategies need to be developed to make the psychosocial care more effective, which are limited time intervention, communication skill improvement, clients' involvement and combination of medication with psychosocial treatment. 


\section{Acknowledgement}

Author would like to thank University of Wollongong Database Sources for all materials provided.

\section{Conflict of Interest}

There is no conflict of interest in this research result.

\section{REFERENCES}

[1]

Amato, L, Minozzi, S, Davoli, M, Vecchi, S, Ferri, M \& Mayet, S 2009, "Psychosocial and pharmacological treatments versus pharmacological treatments for opioid detoxification (Review)", Cochrane Review, vol. 0, no. 3, pp. 1-38 (via CINAHL).

Anthony, W 1993, "Recovery from mental illness : the guiding vision of the mental health service system in the 1990s", Psychosocial Rehabilitation Journal, vol. 16, no. 4, pp. 11-23, University of Wollongong Course Resources Online (GHMB932).

Bradshaw, W \& Roseborough, D 2004, "Evaluating the effectiveness of cognitivebehavioral treatment of residual symptoms and impairment in schizophrenia", Research on Social Work Practice, vol. 14, no. 2, pp. 112-120 (via Health Science).

Bridges, K, Huxley, P \& Oliver, J 1994, "Psychiatric rehabilitation: Redefined for the 1990s", International Journal of Social Psychiatry, vol. 40, no. 1, pp. 1-16 (via Health Science).

Browne, S 1999, "Rehabilitation programs and quality of life in severe mental illness", International Journal of Social Psychiatry, vol. 45, no. 4, pp. 302-309 (via Health Science).

Bustillo, J, Lauriello, J, Horan, W \& Keith, S 2001, "The psychosocial treatment of schizophrenia: an update", American Journal of Psychiatry, vol. 158, no. 2, pp. 163-175 (via CINAHL).

Caldwell, B, Sclafani,M, Swarbrick, M \& Piren, K 2010, "Psychiatric nursing practice \& the recovery model of care", Journal of Psychosocial Nursing \& Mental Health Services, vol. 48, no. 7, pp. 42-48 (via CINAHL).

Chalifoux, Z, Neese, J, Buckwalter, K, Litwak, E \& Abraham, I 1996, "Mental health services for rural elderly: innovative service strategies", Community Mental Health Journal, vol. 32, no. 5, pp. 463-480 (via CINAHL).

Coldham, E, Addington, J \& Addington, D 2002, "Medication adherence of individuals with a first episode of psychosis", Acta Psychiatrica Scandinavica, vol. 106, no. 4, pp. 286-290 (via CINAHL).

Fenton, W, Blyler, C \& Heinssen, R 1997, "Determinants of medication compliance in schizophrenia: Empirical and clinical findings", Schizophrenia Bulletin, vol. 23, no. 4, pp. 637-651 (via CINAHL).

Harvard Mental Health Letter, 2001, "The psychosocial treatment of schizophrenia -part I', vol. 18, no. 2, pp. 1-4 (via CINAHL). 
[12] Harvard Mental Health Letter, 2001, "The psychosocial treatment of schizophrenia -part 2", vol. 18, no. 3, pp. 1-4 (via CINAHL).

[13] Henderson, J, Willis, J, Walter, B \& Toffoli, L 2008, "Community mental health nursing: Keeping pace with care delivery?", International Journal of Mental Health Nursing, vol. 17, no. 3, pp. 162-170 (via CINAHL).

[14] Herrman, H, Trauer, T, Warnock, J 2002, "The roles and relationships of psychiatrists and other service providers in mental health services", Australian and New Zealand Journal of Psychiatry, vol. 36, no. 1, pp. 75-80 (via CINAHL).

[15] MacNeela, P, Clinton G, Place, C, Scott A, Treacy, P, Hyde, A \& Dowd, H 2010, "Psychosocial care in mental health nursing: a think aloud study", Journal of Advanced Nursing, vol. 66, no. 6, pp. 1297-1307 (via CINAHL).

[16] Miklowitz, D, Otto, M, Frank, E, Reilly-Harrington, N, Kogan, J, Sachs, G, Thase, M, Calabrese, J, Marangell, L \& Ostacher, M 2007, "Intensive psychosocial intervention enhances functioning in patients with bipolar depression: results from a 9-month randomized controlled trial", American Journal of Psychiatry, vol. 164, no. 9, pp. 1340-1347(via CINAHL).

[17] Nose, M, Barbui, C \& Tansella, M 2003, "How often do patients with psychosis fail to adhere to treatment programmes? A systematic review", Psychological Medicine, vol. 33, no. 7, pp. 1149-1160 (via CINAHL).

[18] Olatunji, B, Cisler, J \& Deacon, B 2010, "Efficacy of cognitive behavioral therapy for anxiety disorders: a review of meta-analytic findings", Psychiatric Clinics of North America, vol. 33, no. 3, pp. 557-577 (via CINAHL).

[19] Olfson, M, Marcus, S, Wilk, J \& West, J 2006, "Awareness of illness and Non adherence to antipsychotic medications among persons with schizophrenia" Psychiatric Services, vol. 57, no.2, pp. 205-211 (via CINAHL).

[20] Pitschel-Walz, G, Bauml, J, Gsottschnider, A \& Jahn, T 2009,“ Do individuals with schizophrenia and a borderline intellectual disability benefit from psychoeducational groups?", Journal of Intellectual Disabilities, vol. 13, no. 4, pp. 305-320 (via Health Science).

[21] Roe, D \& Swarbrick, M 2007, "A recovery-oriented approach to psychiatric medication: GUIDELINES FOR NURSES", Journal of Psychosocial Nursing \& Mental Health Services, vol. 45, no. 2, pp. 35-40 (via Proquest Central).

[22] Secker, J, Pidd, F, Parham, A \& Peck, E 2000, "Mental health in the community: roles, responsibilities and organisation of primary care and specialist services", Journal of Interprofessional Care, vol. 14, no. 1, pp. 49-58 (via CINAHL).

[23] Shattell, M, Starr, S \& Thomas, S 2007, "Take my hand, help me out': Mental health service recipients' experience of the therapeutic relationship", International Journal of Mental Health Nursing, vol. 16, no. 4, pp. 274-284 (via CINAHL).

Simpson, A 2005, "Community psychiatric nurses and the care co-ordinator role: squeezed to provide 'limited nursing", Journal of Advanced Nursing, vol. 52, no. 6, pp. 689-699 (via CINAHL). 
[25] Tsuang, J, Fong, T \& Lesser, I 2006, "Psychosocial treatment of patients with schizophrenia and substance abuse disorders", Addictive Disorder and Their Treatment, vol. 5, no. 2, pp. 53-66 (via CINAHL).

[26] Verdoux, H, Lengronne, J, Liraud, F, Gonzales, B, Assens, F, Abalan, F \& Van Os, J 2000, "Medication adherence in psychosis: Predictors and impact on outcome. A 2-year follow-up of first-admitted subjects", Acta Psychiatrica Scandinavica, vol. 102, no. 3, pp. 203-210 (via CINAHL). 